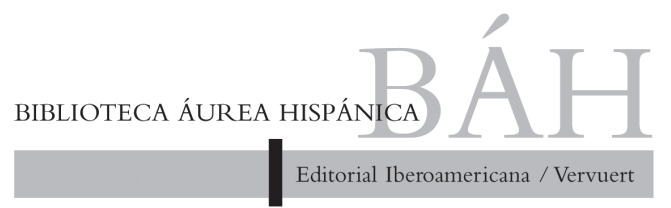

Dirección de Ignacio Arellano (Universidad de Navarra, Pamplona)

con la colaboración de Christoph Strosetzki

(Westfälische Wilhelms-Universität, Münster)

y Marc Vitse

(Université de Toulouse Le Mirail/Toulouse II)

Consejo asesor:

Patrizia Botta

Università La Sapienza, Roma

José María Díez Borque

Universidad Complutense, Madrid

Ruth Fine

The Hebrew University of Jerusalem

Edward Friedman

Vanderbilt University, Nashville

Aurelio González

El Colegio de México

Joan Oleza

Universidad de Valencia

Felipe Pedraza

Universidad de Castilla-La Mancha, Ciudad Real

Antonio Sánchez Jiménez

Université de Neuchâtel

Juan Luis Suárez

The University of Western Ontario, London

Edwin Williamson

University of Oxford

Biblioteca Áurea Hispánica, 138 


\section{HERÓDOTO EN EL SIGLO DE ORO}

Fragmentos históricos y literarios

Giuseppe Marino 
Cualquier forma de reproducción, distribución, comunicación pública o transformación de esta obra solo puede ser realizada con la autorización de sus titulares, salvo excepción prevista por la ley. Diríjase a CEDRO (Centro Español de Derechos Reprográficos) si necesita fotocopiar o escanear algún fragmento de esta obra.

(www.conlicencia.com; $917021970 / 9327204$ 47)

Reservados todos los derechos

(C) Iberoamericana, 2021

Amor de Dios, 1 - E-28014 Madrid

Tel.: +34914293522 - Fax: +34914295397

(C) Vervuert, 2021

Elisabethenstr. 3-9 - D-60594 Frankfurt am Main

Tel.: +49695974617 - Fax: +49695978743

info@iberoamericanalibros.com

www.iberoamericana-vervuert.es

ISBN 978-84-9192-186-8 (Iberoamericana)

ISBN 978-3-96869-103-9 (Vervuert)

ISBN 978-3-96869-104-6 (e-Book)

Depósito Legal: M-1479-2021

Cubierta: Carlos Zamora

Impreso en España

Este libro está impreso íntegramente en papel ecológico sin cloro. 
